\title{
Research on Bathroom Product Design Based on Barrier-free Experience Demand under Digital Background
}

\author{
CHEN Fei-fei ${ }^{1}$ \\ ${ }^{1}$ Foshan University, Foshan, China
}

\begin{abstract}
Objective to study the design of bathroom products based on barrier-free experience requirements under digital background, Method to taking the experience needs of special populations as the research object, by analyzing the senses, emotions, thinking, behaviors, and related experiences of the elderly, the disabled, women, and children in the bathroom process, Conclusion the design of sanitary products with barrier-free experience needs should start from the three experience levels of instinct, behavior and reflection, and follow the design principles of safety and ease of use. Integrate the physical needs, psychological needs and experience needs of the elderly, the disabled, women, and children to make sanitary products more suitable for special populations, and realize all the experiences of elderly, disabled, women and children in the sanitary process Demand as a whole system design.
\end{abstract}

\section{Introduction}

China's bathroom industry has a history of nearly 50 years since the 1970s. In this process, China's bathroom industry has experienced a development stage from imitation to OEM to self-branding. Throughout the whole process, China's bathroom industry has developed rapidly. With the development of science and technology driving the progress of various industries, people's demand for bathroom products has also changed under the digital environment, and the design of barrier-free bathroom products has attracted more attention from consumers. The design of barrier-free bathroom products can not only facilitate the use of normal people, but also solve the problem of self-care for special people, so it is of great significance to pay attention to the design of barrier-free bathroom products.

\section{Experience needs of barrier-free special people}

According to official statistics, it is estimated that the population over 60 years old in China will reach 300 million by 2025 , and the aging process of China's population will reach its peak by 2040 . According to the data of China's sixth census, the total number of disabled people in China in 2010 was 85.02 million[1]. According to the above official statistics, both the elderly and the disabled in China should be a group worthy of special attention. Besides the elderly and the disabled, pregnant women and children are also vulnerable groups, so the special groups concerned in this paper include the elderly, the disabled, women and children. However, since the reform and opening up, our country has developed economically, the material level has gradually improved, and the attention to the needs of special people's sanitary products has also provided some basic facilities and guarantees. However, due to the general weakness of barrier-free awareness and unreasonable design of facilities, special people can get the opportunity to enter ordinary people's living space, but they cannot participate in ordinary people's living environment equally.

\subsection{Experience needs of the elderly}

With the rapid development of China's economic construction and the acceleration of the pace of life of young people, some of them are the needs of young people to go out to work, the other is the needs of the way of life of young people and the elderly, each of which needs independent living space. Therefore, it has become a common phenomenon for the elderly to live alone. In China, citizens over 60 years old are defined as the elderly. As the age increases, the physiological function of the elderly gradually degenerates, the joints are inflexible, the bones are fragile, and the vision, hearing, touch, smell and balance are obviously decreased, reflecting the dull [2]. These physiological symptoms will bring great difficulties to the elderly's ability to take care of themselves alone. From the psychological level analysis, the elderly living alone will appear loneliness, lack of security. The elderly always adhere to a frugal lifestyle, although they have retired, but in life they also have the need to achieve themselves, accompanied by nostalgia to recall their good years.

Based on the psychological and physiological characteristics of the elderly, barrier-free design of bathroom space is a practical concern for the elderly living alone. Based on the physiological and psychological characteristics of the elderly, the bathroom 
products with the characteristics of safety, ease of use, care and warmth are the key directions of the research and development of the bathroom for the elderly. The design of bathroom products for the elderly can not only solve the potential safety hazards in the process of bathroom for the elderly, but also make the children who go out to work with peace of mind, and at the same time reduce the burden on the society and reduce the occurrence of unnecessary safety accidents. Therefore, the design of bathroom products based on the experience needs of the elderly is an inevitable trend of social development.

\subsection{Experience needs of disabled people}

People with disabilities in this paper include people with visual disability, hearing disability, speech disability, physical disability, intellectual disability, mental disability, multiple disabilities and other disabilities [3]. This paper focuses on the analysis of lower limb disability and visual disability groups, which can represent the mobility disorder of the disabled, meet their needs and meet other disabled user groups.

Disabled people are a group that needs special care. Because of the inconvenience caused by their congenital or acquired disabilities, they have a strong demand for self-esteem. Especially in places with personal privacy, such as personal washing and bathing and toilets, they need to be respected, so it is necessary to design and develop bathroom products for the disabled. In fact, the disabled are similar to the elderly in some aspects, because with the growth of people's age and the deterioration of their physical functions, the elderly will have problems in vision, hearing, spirit and limbs to varying degrees. Therefore, we must combine the common experience needs of the elderly and the disabled while developing the bathroom for the disabled, so as to make our bathroom products more applicable and versatile, and maximize the value. The psychological characteristics of the disabled are loneliness, inferiority complex, sensitivity, strong self-esteem, strong and unstable emotional response, compassion, etc. According to the physiological and psychological characteristics of the disabled, we should tailor the bathroom products suitable for them, and adhere to the principles of caring, warmth, ease of use, safety and empathy.

\subsection{Experience needs of pregnant women and children}

Women and children are two integrated groups. Women here include pregnant women and women with infants, and children include infants and children groups. In the real public environment, many places do not consider the special experience needs of pregnant women and women. During the ten-month pregnancy, pregnant women are physically inconvenient, so they need auxiliary safety facilities for going to the toilet and bathing. The most troublesome thing for women with children when going out is that when going to the toilet, infants have to carry them on their backs all the time, causing great inconvenience. At the same time, it is difficult to find a place to change clothes and diapers for infants in public health space, and a safe and private nursing space. In addition, there is a need for household bathroom products specially designed for women with special physiological and health needs, and bathroom products specially designed and developed for children. Based on the physiological and psychological needs of women and children in these special stages, the principles of comfort, health, care and safety should be adhered to in the design and development [5].

\section{The Present Situation of Bathroom Product Design Based on Barrier-free Experience Demand at Home and abroad under Digital Background}

Under the digital background, the development of barrier-free bathroom products in our country is still far behind that in foreign countries. The design of barrier-free bathroom products in China is still in the primary stage, while the design of barrier-free bathroom products in foreign countries is in the intermediate stage.

\subsection{Development situation of barrier-free bathroom products in China}

Since the end of 1990s, the design of barrier-free bathroom products in China has gone through a process from unconsciousness to weak consciousness to gradual improvement. Barrier-free design of bathroom product design is a specific barrier-free facility design based on space and indoor environment. Based on the standards and specifications of barrier-free building and interior design issued by the government, the design of barrier-free bathroom products has been placed in specific spaces in major public places. Careful observation reveals that these barrier-free bathroom devices are basically occupied by the public in appearance, and they are not really used, but cause troubles for special people. Lack of public awareness of barrier-free bathroom, insufficient investment in research and development of barrier-free bathroom by enterprises, and lack of attention by the government are all the reasons for the lag in research and development and innovation of barrier-free bathroom products in China. Enterprises think that there is no market demand, while China is a big country with special population, and basically every household has to face the existence of one of the elderly, children, pregnant women and disabled people. The ability to take care of themselves, which should have been done by themselves, and the fact that we do everything not only makes them lose the pleasure of life, but also makes them lose their sense of existence and value, and at the same time increases the pressure and troubles of our care and care. Even in homes for the elderly, kindergartens, hospitals, schools for special people and other places, only plastic urinals and urinals are used to help them complete the simple sanitary bathing process. In this process, barrier-free people lose their dignity and happiness, and feel pain and privacy leakage. Whether it is home or 
public space, barrier-free bathroom products are the direction that we should explore. From this point of view, there is still a long way to design barrier-free bathroom products in China, which requires multi-party cooperation and efforts to promote the functional innovation and system improvement of barrier-free bathroom product design in China, and truly realize the comfortable experience of special people in the bathroom process [6].

\subsection{Development status of barrier-free bathroom product abroad}

Foreign barrier-free design concepts are relatively mature in the thinking of the public and designers. Western countries can truly realize the self-care of special people because their barrier-free facilities are very systematic and complete. There are special barrier-free bathroom spaces and supporting facilities in public places and family sanitary spaces, which are highly respected by the public and can be truly applied. Western countries emphasize the cultivation of life independence and self-care ability of special people, so that special people can feel full respect and happy experience in the process of bathing. Japan has been aging since 1970s. The government and enterprises attach great importance to R\&D and design investment of barrier-free bathroom products. Japan has made a detailed division and distinction between the elderly, the disabled, children and women. At present, Japan's barrier-free bathroom facilities are at the world's leading level, and special people living in Japan can feel love, respect and freedom. Whether in the West or Japan, their successful experience in barrier-free bathroom design is worth learning and popularizing.

\section{Principles and Methods Bathroom Product Design Based on Barrier-free Experience Demand under Digital Background}

Through the analysis of the experience needs of barrier-free people, combined with the physiological and psychological needs of the elderly, disabled people, women, children and other special groups. We can divide the experience needs of barrier-free people into three levels. From the psychological point of view and emotional level, it can be divided into instinct level demand, behavior level demand and reflection level demand [7].

\subsection{Experience design of barrier-free bathroom products at instinctive level}

Experience design of barrier-free bathroom products at instinctive level can focus on convenience design principles. Starting from the instinctive experience of barrier-free people, convenience focuses on shape and color, which makes it necessary for barrier-free people to have obvious color recognition when using bathroom products, and facilitate operation and cognition. For example, the operation of water temperature can prompt the approximate safe range of temperature through the change of color, and the switch button should be prompted in red, so that special people can quickly find the switch key. For example, the operation of water temperature can prompt the approximate safe range of temperature through the change of color, and the switch button should be prompted in red, so that special people can quickly find the switch key. The color of bathroom products can also give the barrier-free people warmth in the process of bathroom, instead of all-white giving people a cold feeling. Compared with other people, the psychology and emotion of barrier-free people are more sensitive and sensitive. Therefore, in different barrier-free people such as the elderly, the disabled, women and children, we can combine their age and gender characteristics and psychological needs to give color to specific bathroom product details [9]. As far as possible, some organic shapes are adopted. The lively shapes add hope and fun to life for special people.

\subsection{Experience design of barrier-free bathroom products at behavioral level}

The experiential design of barrier-free bathroom products at the behavioral level is the sublimation at the instinctive level. In the process of further using bathroom products by special people, the safety and pleasure principles of barrier-free bathroom products are mainly considered [8].

Safety principle needs to consider the safety of modeling and materials, adopt rounded structure as far as possible, and avoid sharp angle structure to avoid danger during use. In the design of materials, we should try our best to avoid fragility, and achieve the texture and function of antiskid materials through texture treatment. Make special people feel safe and comfortable during use.

Pleasure design principle mainly considers the sound prompt function of barrier-free bathroom products, which can integrate sound into the functions of barrier-free bathroom products, so that barrier-free people can enjoy leisure and relaxation in the process of bathroom.

\subsection{Experience design of barrier-free bathroom products at reflective level}

The reflective experience design of barrier-free bathroom products is mainly embodied in the design principles of equality and universality [9]. The principle of equality is considered in the design of barrier-free bathroom products, which mainly aims at providing equal privacy, safety and protection to different groups of people under the same use mode of the same bathroom product, so as to avoid the frustration of special groups in the use process. The general design principle should abide by the same product and provide corresponding functional services for different people. Universal design is a design based on human needs, equality for all, love and consideration. From this point of view, universal design is not only caring for people, but also maximizing the value of products and caring for the environment. Universal design principle includes equality design principle [10]. These two design principles embody the reflection thinking of 
human beings in the design of barrier-free bathroom products. This level belongs to the highest level of product design, and it is also the soul level and spiritual level of barrier-free bathroom product design. This is the key direction of our country's barrier-free bathroom product design efforts.

\section{Conclusion}

Through the analysis of barrier-free experience needs, this paper specifically analyzes the requirements of different special people's experience needs for bathroom product design. Combined with the design status of barrier-free bathroom products at home and abroad, it summarizes the principles and methods of barrier-free bathroom design. Barrier-free bathroom product design explores the corresponding design principles and methods from instinct, behavior and reflection. This has the function of spreading great love and positive energy for barrier-free people and society, and it is also the direction of joint efforts of Chinese bathroom enterprises, designers and government.

\section{ACKNOWLEDGEMENT}

Fund projects: Guangdong University Youth Innovative Talents Project (2015xrc02)

\section{AUTHOR INTRODUCTION:}

Chen Feifei (1983-), female, Zhuzhou, Hunan, master's degree, Foshan University, lecturer, Mainly engaged in product design research.

\section{REFERENCES}

1. Chen Haiyan. Research on the design of barrier-free bathroom products [D]. Tianjin: Tianjin University of Science and Technology, 2013.

2. Xuan Wei. Study on the barrier-free design of bathroom facilities for the elderly[J].Packaging Engineering, 2012(02):39-40.

3. Wang Aihong, Sun Ling. Sensory function and design of barrier-free bathroom facilities[J]. Grand View of Fine Arts, 2005 (12): 85.

4. GUO Hui-yao. Experience Design Research Based on the Bathroom Product[J].Decoration, 2012, 232(8): 94-95.

5. Chen Wei. User experience design elements and their application in product design [J]. Packaging Engineering, 2011 (10): 26-27.

6. Zhang Feifei. Research on the barrier-free design of bathing in elderly homes[D]. Beijing: Hebei University, 2018.

7. Donald Arthur Norman. Emotional design[M]. Beijing: Electronic Industry Press, 2005:28-30.

8. Hao Lina. Research on the co-design of household bathroom products adapted to the aging society[D].
Beijing: Tianjin University of Science and Technology, 2012.

9. Wu Ming, Li Lun, Yang Yanxia. Research on bathroom product design from the perspective of "experience"[J]. Journal of Shaanxi University of Science and Technology (Natural Science Edition), 2010(04):151-152.

10. Hu Xiaoxing. Multi-generation household bathroom product design based on universal design concepts[D]. Beijing: Dalian University of Technology, 2016. 